\title{
Desenvolvimento in vitro de Agaricus brasiliensis em meios suplementados com diferentes farelos
}

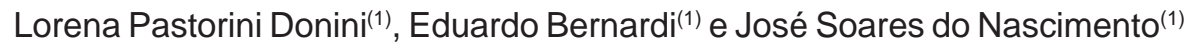

(1)Universidade Federal de Pelotas, Instituto de Biologia, Dep. de Microbiologia e Parasitologia, Caixa Postal 354, CEP 96001-970 Pelotas, RS.
E-mail: Iorenadonini@yahoo.com.br, bernardieduardo@yahoo.com.br, jose@ufpel.tche.br

Resumo - O cogumelo Agaricus brasiliensis normalmente é cultivado em meios à base de batata ou composto orgânico. O objetivo deste trabalho foi avaliar o desenvolvimento in vitro da linhagem ABL 97/11 de A. brasiliensis, cultivada em meio à base de composto suplementado com diferentes concentrações de farelos de milho, trigo, arroz e soja, à temperatura constante de $28^{\circ} \mathrm{C}$. Avaliou-se, diariamente, o diâmetro da colônia e obteve-se, aos seis dias de cultivo, a massa miceliana. A adição de farelos de soja ou arroz não favorece o desenvolvimento in vitro de A. brasiliensis. O meio de cultura suplementado com $20 \%$ de farelo de trigo apresenta as maiores massa miceliana e velocidade de crescimento, comparado aos meios suplementados com outros farelos, na mesma concentração. Na concentração de 10\% de farelo, o milho promove a maior velocidade de crescimento do cogumelo.

Termos para indexação: Himematsutake, velocidade de crescimento, massa miceliana.

\section{In vitro development of Agaricus brasiliensis in media supplemented with different brans}

\begin{abstract}
The mushroom Agaricus brasiliensis is usually grown in potato-based or compost media. The objective of this work was to evaluate the in vitro development of the strain ABL 97/11 of $A$. brasiliensis grown in culture medium supplemented with brans of maize, wheat, rice and soybean, in different concentrations. Cultivation was performed under constant temperature of $28^{\circ} \mathrm{C}$. Diameter of the colony was evaluated daily and after six days of cultivation, mycelial mass was obtained. The addition of soybean or rice brans did not favor the development in vitro of A. brasiliensis. The largest averages of mycelial mass and growth rate are obtained in medium containing $20 \%$ of wheat bran. The medium containing $10 \%$ of maize corn presents the highest growth rate among the different media under the same bran concentration.
\end{abstract}

Index terms: Himematsutake, growth rate, mycelial mass.

\section{Introdução}

Os cogumelos são fungos utilizados na alimentação desde a antigüidade. Cogumelos comestíveis têm atraído o interesse de pesquisadores por suas propriedades não apenas nutritivas, mas potencialmente medicinais. Muitos de seus compostos têm sido avaliados como possíveis substâncias antitumorais e anticancerígenas (Mizuno et al., 1998; Takaku et al., 2001; Rodrigues et al., 2003).

No Brasil, o consumo de cogumelos vem crescendo significativamente, em virtude do valor nutritivo e da disponibilidade do mercado, o que torna o produto mais popular e acessível (Braga \& Eira, 1999).
A espécie Agaricus brasiliensis (Murrill) ss. Wasser (Wasser et al., 2002) pertence à ordem Agaricales, com cerca de trezentos gêneros e aproximadamente cinco mil espécies (Souza \& Aguiar, 2004). O cultivo de A. brasiliensis, no Brasil, tem sido realizado nos meses mais quentes do ano, com pouca tecnologia. Por se tratar de uma espécie que se desenvolve em materiais ricos em lignocelulose, também apresenta bom desenvolvimento em meios de cultura elaborados à base de compostos orgânicos, quando incubados em temperatura de 25 a $29^{\circ} \mathrm{C}$ e umidade relativa de 60 a 90\% (Park et al., 2003).

No cultivo de Agaricus sp., podem ser aproveitados resíduos agroindustriais como substratos 
à base de palha de trigo, palha de arroz, gramíneas e cana-de-açúcar (Eicker, 1995; Eira, 2003). De acordo com Eira \& Minhoni (1997), todo o composto para o cultivo de cogumelos tem como regra o componente volumoso e fibroso à base de palhas de capim e outros materiais fibrosos, ricos em carbono e pobres em $\mathrm{N}$ e P. No cultivo de Agaricus sp., o composto deve ser previamente suplementado com materiais concentrados como farelos e tortas.

Os fungos secretam enzima durante seu desenvolvimento e degradam compostos orgânicos para obtenção de C, N, S e outros nutrientes necessários a seu crescimento. Por isso, para se alcançar rendimentos ótimos na degradação do material lignocelulósico pobre em $\mathrm{N}$, a suplementação desse elemento é essencial (Regina, 2001).

No cultivo de A. bisporus, o composto pode ser suplementado com farelos de soja, uréia, aveia e cereais. Os farelos de arroz e trigo são tradicionalmente utilizados no cultivo de Lentinula edodes (Rossi et al., 2003). O farelo de arroz é uma fonte de nutrientes utilizada para suplementar o substrato bagaço de cana-de-açúcar, por estimular o crescimento miceliano de espécies de cogumelo nesse substrato (Rossi et al., 2001).

A fase miceliana, no substrato, é fundamental para o cultivo de cogumelos, pois quanto mais rápido ocorrer o seu desenvolvimento, menor o risco de contaminação por outros fungos ou bactérias. Na pesquisa com linhagens isoladas, é importante a escolha do meio de cultura adequado para multiplicação do fungo e crescimento miceliano satisfatório de modo a dar seqüência às etapas seguintes da produção (Marino, 1997). O crescimento miceliano pode ser influenciado pela redução na concentração de nutrientes e oxigênio, acúmulo de produtos finais tóxicos, produção de metabólitos secundários e mudanças de fatores como o pH (Regina, 2001).

O objetivo deste trabalho foi avaliar a velocidade de crescimento e a produção de massa miceliana da linhagem ABL 97/11 de A. brasiliensis, em meios de cultivo à base de composto suplementado com diferentes concentrações de farelos.

\section{Material e Métodos}

Este trabalho foi realizado no Laboratório Experimental de Micologia, do Dep. de Microbiologia e Parasitologia, do Instituto de Biologia da Universidade Federal de Pelotas, RS.

No experimento, foi utilizada cultura de A. brasiliensis, linhagem ABL 97/11, preservada em meio de cultura à base de composto-dextroseágar (CDA) (Eira \& Minhoni, 1997), à temperatura ambiente.

A cultura foi repicada para placas de Petri, contendo o meio CDA, que foram incubadas a $28 \pm 1^{\circ} \mathrm{C}$ até o crescimento miceliano em toda a placa. Depois do crescimento, foi realizado o processo de adaptação, que consistiu de repicagem do micélio para placas de Petri com meio CDA suplementado com 0, 10 e $20 \%$ dos farelos de soja, trigo, milho e arroz; as placas foram incubadas nas condições descritas anteriormente, até o crescimento miceliano. Discos de cultura de $10 \mathrm{~mm}$ dos respectivos meios foram novamente repicados para cada meio correspondente, totalizando 12 tratamentos. As placas foram incubadas nas mesmas condições.

O crescimento miceliano foi medido com o auxílio de uma régua, em oito direções ortogonais, a cada 24 horas, durante a incubação, até o momento em que uma colônia atingiu a proximidade das bordas da placa em um dos tratamentos, o que ocorreu no sexto dia de incubação. Depois da última avaliação do crescimento, o meio de cultura foi dissolvido em água fervente, aproximadamente $500 \mathrm{~mL}$, recolhendo-se a massa miceliana úmida (Mmu) com o auxílio de alça de platina, colocada sobre papel-manteiga e levada para secar em estufa a $50^{\circ} \mathrm{C}$, por 24 horas, para a obtenção da massa miceliana seca (Mms) (Nascimento, 2003).

$\mathrm{O}$ experimento foi conduzido em delineamento inteiramente casualizado e constou de um fatorial A x B x C ( $\mathrm{A}=$ farelos, $\mathrm{B}=$ concentrações e $\mathrm{C}=$ dias de incubação), para a variável velocidade de crescimento, e A x B, para a variável massa miceliana. A unidade experimental constou de uma placa de Petri, com seis repetições por tratamento. Os resultados foram submetidos à análise da variância e teste de Duncan para comparação das médias, utilizando-se o programa estatístico Sanest (Zonta \& Machado, 1984). 


\section{Resultados e Discussão}

Para a variável massa miceliana, houve diferenças significativas na interação entre os farelos e as concentrações utilizadas. Nos tratamentos com adição de farelos de soja e arroz, houve efeito de redução de massa miceliana, quando comparados aos sem adição de farelos (Tabela 1). Isso pode ter ocorrido porque a adição dos farelos aumentou a concentração de $\mathrm{N}$, como no caso do farelo de soja, que contém até 7,38\% de N (Eira \& Minhoni, 1997). $\mathrm{O}$ excesso de $\mathrm{N}$ tende a reprimir a degradação da lignina, retardando ou até inibindo o aparecimento do micélio (Zanetti \& Ranal, 1997; Oliveira \& Urben, 2001). De acordo com Regina (2001), em alguns casos, as fontes de $\mathrm{N}$ mais simples aumentam a concentração de proteínas das culturas, diminuem o crescimento miceliano e a degradação da lignina.

Farelos de trigo e de milho não influenciaram o aumento da biomassa miceliana. Quando se utilizaram concentrações de 10 e $20 \%$, os farelos de trigo e milho mostraram-se superiores aos demais, nas mesmas concentrações, porém não ultrapassaram os valores médios alcançados no tratamento sem adição de farelos. Soto-Cruz et al. (1999), ao avaliar diferentes substratos no cultivo de Pleurotus ostreatus, verificaram que a utilização de concentrações altas de farelo de aveia proporcionou maior perda de matéria seca e redução indesejável da taxa de crescimento.

Os farelos de soja e de arroz ocasionaram redução da velocidade de crescimento (Tabela 2). No cultivo de Pleurotus sajor-caju, Dias et al. (2003) postularam que substância presente em alguns dos resíduos agrícolas

Tabela 1. Massa miceliana (g) da linhagem ABL 97/11 de Agaricus brasiliensis, seis dias após o cultivo in vitro, nos meios com diferentes farelos e concentrações ${ }^{(1)}$.

\begin{tabular}{lccc}
\hline Farelos & \multicolumn{3}{c}{ Concentração (\%) } \\
\cline { 2 - 4 } & 0 & 10 & 20 \\
\hline Soja & $0,017 \mathrm{aA}$ & $0,010 \mathrm{bB}$ & $0,011 \mathrm{bB}$ \\
Trigo & $0,017 \mathrm{aA}$ & $0,013 \mathrm{aB}$ & $0,019 \mathrm{aA}$ \\
Arroz & $0,017 \mathrm{aA}$ & $0,009 \mathrm{bB}$ & $0,009 \mathrm{bB}$ \\
Milho & $0,017 \mathrm{aA}$ & $0,015 \mathrm{aA}$ & $0,017 \mathrm{aA}$ \\
\hline
\end{tabular}

(1)Médias seguidas de mesma letra, minúscula nas colunas e maiúscula nas linhas, não diferem entre si pelo teste de Duncan a 5\% de probabilidade. testados pode ter inibido o crescimento miceliano do fungo. No cultivo de Lentinula edodes, Rossi et al. (2003) observaram que a miceliação diminuiu significativamente com a utilização de proporções crescentes de farelo de arroz. A adição desse suplemento promoveu declínio gradual na relação C:N do substrato.

No tratamento com adição de $20 \%$ de farelo de trigo, foram obtidas as maiores médias de velocidade de crescimento, comparado aos demais farelos, na nessa concentração (Tabela 2). Na concentração de $10 \%$ de farelo, o milho proporcionou maior velocidade de crescimento. Ao contrário dos resultados satisfatórios encontrados com a utilização de farelo de trigo neste trabalho, Dias et al. (2003) verificaram efeito negativo, quando o farelo de trigo foi adicionado à palha de feijão, no cultivo de Pleurotus sajor-caju. Neste caso, o farelo dificultou a colonização do substrato, porém a adição do mesmo farelo à palha de milho não afetou o crescimento do micélio, possibilitando aumento da eficiência biológica.

A adição de farelos de soja e arroz, ao meio CDA, ocasiona redução da velocidade de crescimento de A. brasiliensis (Figura 1). O meio de cultura que proporcionou maior velocidade de crescimento foi o suplementado com $20 \%$ de farelo de trigo. A concentração de $10 \%$ de farelo de milho proporcionou maior velocidade de crescimento do que o tratamento com 20\% desse farelo (Figura 1). Moda et al. (2005), com o cultivo de P. sajor-caju em bagaço de cana-de-açúcar suplementado com quirela de milho e solução mineral, observaram menor eficiência biológica do cogumelo no cultivo suplementado com quirela de milho.

Tabela 2. Velocidade média de crescimento ( $\left.\mathrm{cm} \mathrm{dia}^{-1}\right)$ da linhagem ABL 97/11 de Agaricus brasiliensis, seis dias após o cultivo in vitro, nos meios com diferentes farelos e concentrações ${ }^{(1)}$.

\begin{tabular}{lccc}
\hline Farelos & \multicolumn{3}{c}{ Concentração (\%) } \\
\cline { 2 - 4 } & 0 & 10 & 20 \\
\hline Soja & $2,705 \mathrm{aA}$ & $1,534 \mathrm{~dB}$ & $1,469 \mathrm{dC}$ \\
Trigo & $2,705 \mathrm{aC}$ & $2,860 \mathrm{bB}$ & $3,241 \mathrm{aA}$ \\
Arroz & $2,705 \mathrm{aA}$ & $1,828 \mathrm{cB}$ & $1,749 \mathrm{cB}$ \\
Milho & $2,705 \mathrm{aB}$ & $3,197 \mathrm{aA}$ & $2,731 \mathrm{bB}$ \\
\hline
\end{tabular}

(1)Médias seguidas de mesma letra, minúscula nas colunas e maiúscula nas linhas, não diferem entre si pelo teste de Duncan a 5\% de probabilidade. 


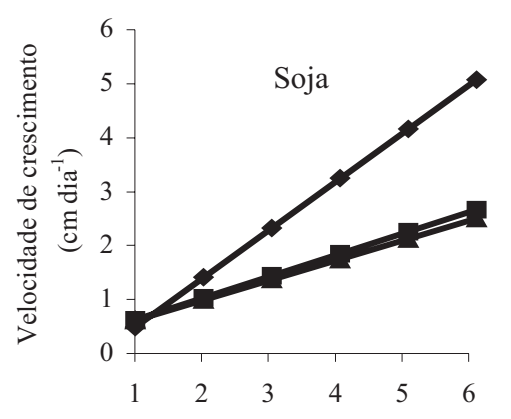

$$
\begin{gathered}
y=0,9213 x-0,5187 \\
r^{2}=0,9937 \\
y=0,4102 x+0,1288 \\
r^{2}=0,9951 \\
y=0,3781 x+0,146 \\
r^{2}=0,9946
\end{gathered}
$$

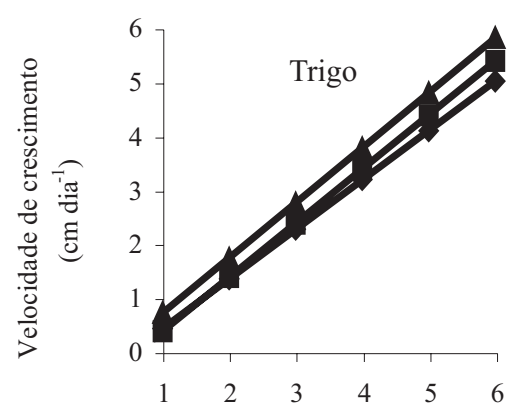

$y=1,0244 x-0,3435$

$r^{2}=0,9978$

$\mathrm{y}=1,0093 \mathrm{x}-0,6722$

$\mathrm{r}^{2}=0,9923$

$\mathrm{y}=0,9213 \mathrm{x}-0,5187$

$r^{2}=0,9937$

$$
\text { r }
$$

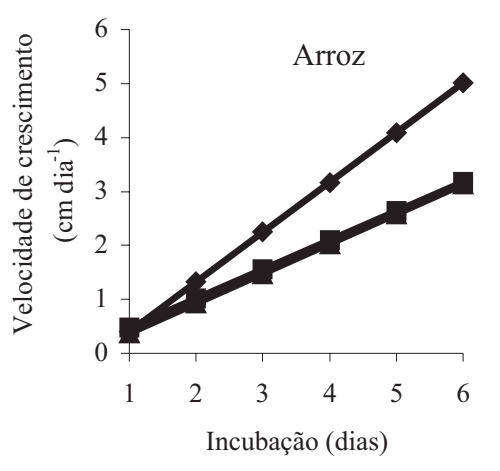

$$
\begin{gathered}
y=0,9213 x-0,5187 \\
r^{2}=0,9937 \\
y=0,5409 x-0,0646 \\
r^{2}=0,9935 \\
y=0,554 x-0,1892 \\
r^{2}=0,9899
\end{gathered}
$$

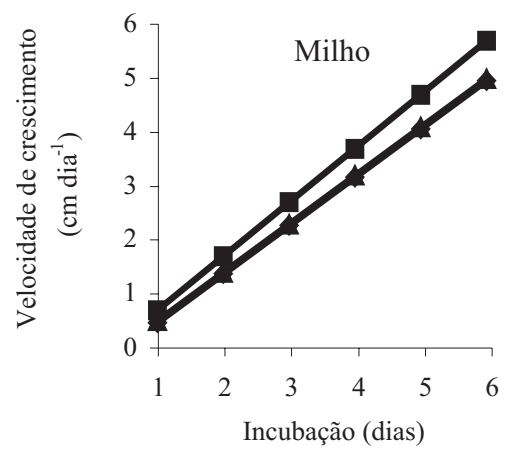
$y=1,0283 x-0,4012$ $\mathrm{r}^{2}=0,9953$
$\mathrm{y}=0,9213 \mathrm{x}-0,5187$
$r^{2}=0,9937$
$\mathrm{y}=0,9209 \mathrm{x}-0,4918$
$r^{2}=0,9890$

Controle

$\mathrm{CDA}+10 \%$ do farelo

$\Delta \mathrm{CDA}+20 \%$ do farelo

Figura 1. Velocidade de crescimento da linhagem ABL 97/11 de Agaricus brasiliensis em meio de cultura à base de compostodextrose-ágar (CDA) suplementado com farelos de soja, trigo, arroz e milho.

\section{Conclusões}

1. O meio de cultura suplementado com $20 \%$ de farelo de trigo proporciona as maiores massa miceliana e velocidade de crescimento para Agaricus brasiliensis, linhagem ABL 97/11.

2. Na concentração de $10 \%$, o farelo de milho ocasiona maior velocidade de crescimento da linhagem ABL 97/11, comparado aos farelos de trigo, arroz e soja na mesma concentração.

\section{Agradecimentos}

À Capes e ao CNPq, pela concessão de bolsas de mestrado as autores.

\section{Referências}

BRAGA, G.C.; EIRA, A.F. da. Efeitos da camada de cobertura, da massa do substrato e do ambiente de cultivo, na produtividade de Agaricus blazei Murril. Engenharia na Agricultura, v.14, p.39-52, 1999.
DIAS, E.S.; KOSHIKUMO, E.M.S.; SCHWAN, R.F.; SILVA, R. Cultivo do cogumelo Pleurotus sajor-caju em diferentes resíduos agrícolas. Ciência e Agrotecnologia, v.27, p.1363-1369, 2003.

EICKER, A. The South African experience in growing Pleurotus spp. In: ELLIOTT, T.J. (Ed.). Science and cultivation of edible fungi. Rotterdam: A.A. Balkema, 1995. v.2, p.869-875.

EIRA, A.F. da. Cultivo do “cogumelo-do-sol” Agaricus blazei (Murrill) ss. Heinemann. Viçosa: Aprenda Fácil, 2003. 203p.

EIRA, A.F. da; MINHONI, M.T.A. Manual teórico-prático do cultivo de cogumelos comestíveis. 2.ed. Botucatu: Fundação de Estudos e Pesquisas Agrícolas e Florestais, 1997. 115p.

MARINO, R.H. Produtividade do Pleurotus sajor-caju (Fr.) Sing. em função dos métodos de isolamento e produção de inoculantes. 1997. 134p. Dissertação (Mestrado) - Universidade Estadual Paulista, Araraquara.

MIZUNO, M.; MORIMOTO, M.; MINATO, K.; TSUCHIDA, H. Polysaccharides from Agaricus blazei stimulate lymphocyte T-cell subsets in mice. Bioscience, Biotechnology and Biochemistry, v.62, p.434-437, 1998.

MODA, E.M.; HORRI, J.; SPOTO, M.H.F. Edible mushroom Pleurotus sajor-caju production on washed and supplemented sugarcane bagasse. Scientia Agricola, v.62, p.127-132, 2005. 
NASCIMENTO, J.S. Etiologia, controle e demanda de energia na prevenção da falsa trufa em cultivos de Agaricus blazei. 2003. 111p. Tese (Doutorado) - Universidade Estadual Paulista, Botucatu.

OLIVEIRA, H.C.B.; URBEN, A.F. Cultivo de Pleurotus sp. utilizando a técnica "Jun-Cao". In: URBEN, A.F. Produção de cogumelos por meio da tecnologia chinesa modificada. Brasília: Embrapa Recursos Genéticos e Biotecnologia, 2001. 151p.

PARK, Y.K.; IKEGAKI, M.; ALENCAR, S.M.; AGUIAR, C.L. Determinação da concentração de $\beta$-glucano em cogumelo Agaricus blazei Murril por método enzimático. Ciência e Tecnologia de Alimentos, v.23, p.312-316, 2003.

REGINA, M. Cinética do crescimento miceliano de Lentinula edodes (Berk.) Pegler em bagaço de cana-de-açúcar e serragem de eucalipto. 2001. 87p. Dissertação (Mestrado) - Universidade Estadual Paulista, Botucatu.

RODRIGUES, S.B.; JABOR, I.A.S.; MARQUES-SILVA, G.G.; ROCHA, C.L.M.S.C. Avaliação do potencial antimutagênico do Cogumelo-do-sol (Agaricus blazei) no sistema menthG1 em Aspergillus (=Emericella) nidulans. Acta Scientiarum, v.25, p.513-517, 2003.

ROSSI, I.H.; MONTEIRO, A.C.; MACHADO, J.O. Desenvolvimento micelial de Lentinula edodes como efeito da profundidade e suplementação do substrato. Pesquisa Agropecuária Brasileira, v.36, p.887-891, 2001.

ROSSI, I.H.; MONTEIRO, A.C.; MACHADO, J.O.; BARBOSA, J.C. Supplementation of sugarcane bagasse with rice bran and sugarcane molasses for Shiitke (Lentinula edodes) spawn production. Brazilian Journal of Microbiology, v.34, p.61-65, 2003.

SOTO-CRUZ, O.; SAUCEDO-CASTAÑEDA, G.; PABLOSHACH, J.L.; GUTIÉRREZ-ROJAS, M.; FAVELA-TORRES, E. Effect of substrate composition on the mycelial growth of Pleurotus ostreatus. An analysis by mixture and response surface methodologies. Process Biochemistry, v.35, p.127-133, 1999.

SOUZA, H.Q. de; AGUIAR, I. de J.A. Diversidade de Agaricales (Basidiomycota) na Reserva Biológica Walter Egler, Amazonas, Brasil. Acta Amazônica, v.34, p.43-51, 2004.

TAKAKU, T.; KIMURA, Y.; OKUDA, H. Isolation of an antitumor compound from Agaricus blazei (Murril) and its mechanism of action. Journal of Nutrition, v.131, p.1409-1413, 2001.

WASSER, S.P.; DIDUKH, M.Y.; AMAZONAS, M.A.L. de; NEVO, E.; STAMETS, P.; EIRA, A.F. da. Is a widely cultivated culinarymedicinal Royal Sun Agaricus (the himematsutake mushroom) indeed Agaricus blazei Murrill? International Journal of Medicinal Mushrooms, v.4, p.267-290, 2002.

ZANETTI, A.L.; RANAL, M.A. Suplementação da cana-de-açúcar com guandu no cultivo de Pleurotus sp. 'Florida'. Pesquisa Agropecuária Brasileira, v.32, p.959-964, 1997.

ZONTA, E.P.; MACHADO, A.A. SANEST: sistema de análise estatística para microcomputadores. Pelotas: Universidade Federal de Pelotas, 1984. 151p.

Recebido em 27 de julho de 2005 e aprovado em 3 de janeiro de 2006 